\title{
Tracking technique for the sudden change of PV inverter load
}

\author{
Amer Tayes Saeed ${ }^{1}$, Mohamed Qasim Taha ${ }^{2}$, Abdullah Khalid Ahmed ${ }^{3}$ \\ ${ }^{1}$ College of Petroleum and Minerals, University of Tikrit, Iraq \\ 2, College of Applied Sciences-Hit, University of Anbar, Iraq \\ ${ }^{3}$ College of Engineering, University of Anbar, Iraq
}

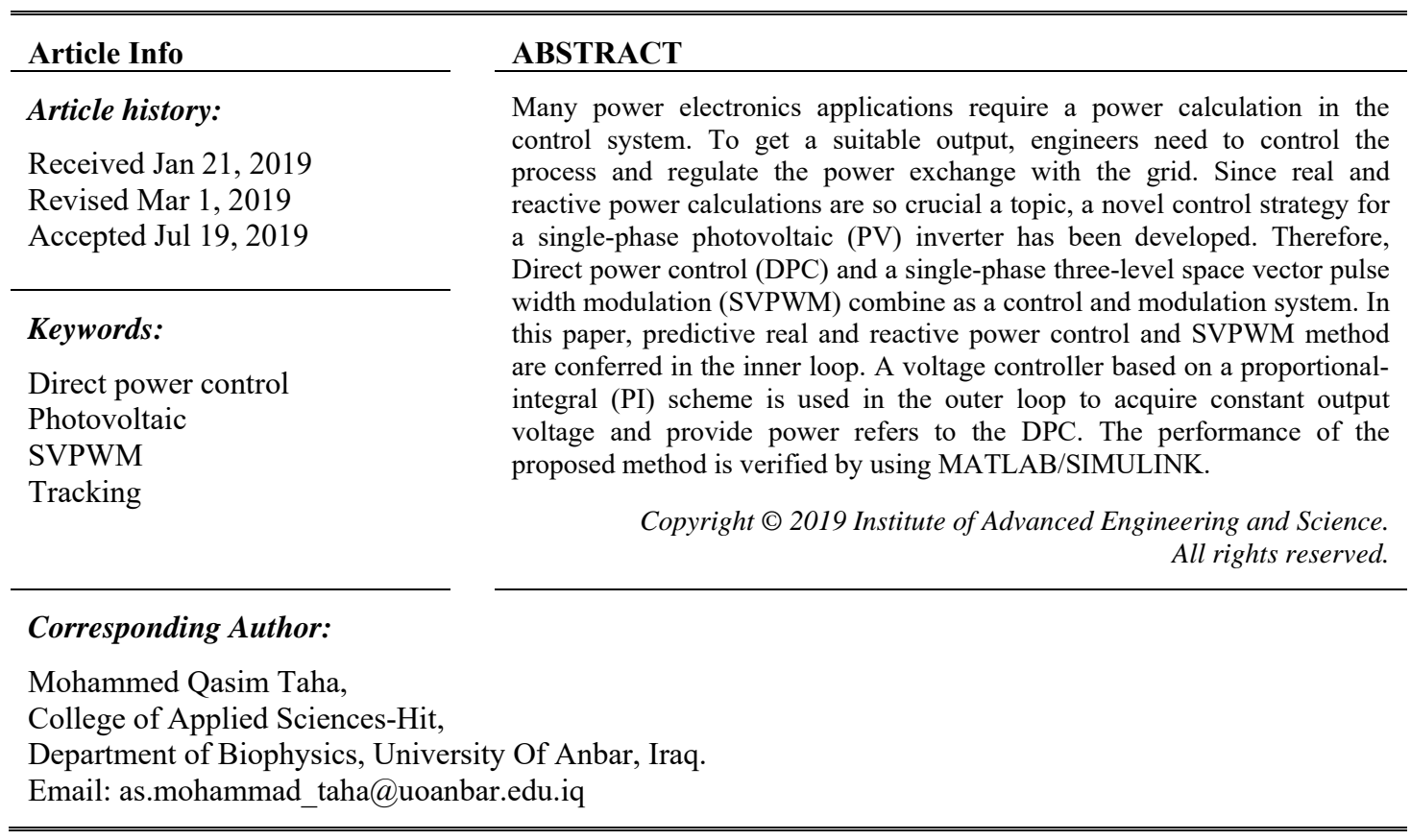

\section{INTRODUCTION}

Due to global warming issues and air quality deterioration, green energy sources are widely used to solve these problems or at least to decrease the effects of using coal, natural gas, or petroleum. PV systems are one of these green energy resources, which are converting sunlight to electrical energy; PV systems are dependent on two things: irradiation and temperature. Nowadays, PV systems have been hugely dispersed in the distribution systems. These fast growing in the PV systems generation will help stabilize utility, climate change and air pollution $[1,2]$.

Since the PV solar panel is considered a sporadic power source, it should be monitored. Therefore, the focus of the study is about the control of active and reactive power in the PV panels. To get the desired output and to regulate the power exchange with the grid, the process needs to be controlled, and at the same time, the effect of harmonic components in the alternating current (AC) side should be limited. In [3] the PV panel reactive power used to improve drop voltage and low power factor in the distribution systems, most of these strategies use the d-q control scheme [4]. The control method in [4] used the adaptive filter to the monitor grid current. Some studies focused on controlling the real power in the distribution systems by using different control methods due to the necessity of improving the active power to provide the rising demand [5, $6]$.

In [7] the transformation methods have been used as a base for these controlling strategies to achieve a better outcome. DPC has been used widely in controlling the power with different strategies. In order to control active and reactive power two strategies for current injection grid-connected photovoltaic systems were proposed in [8]. To get an optimal current from the PV system double-loop control strategy to improve the output of the solar panel. The MPPT algorithm was integrated with a double-loop control strategy to improve the output of the solar panel [9]. A strategy for a single-phase H-Bridge inverter led to 
the load current achieving the compensation of the reactive power used in [10]. To improve the THD, the accuracy of the output magnitude, and block the DC component, a PWM switching technique for multilevel converters presented in [11],[12]

This study is focused on an SVPWM-DPC strategy to calculate the active and reactive power in the single-phase system. To get maximum PV generation, a maximum power point tracker (MPPT) algorithm has been integrated with the proposed methods. The performance of the proposed methods is evaluated by simulation results obtained using MATLAB/Simulink.

\section{MODELING \& SIMULATION}

This strategy focuses on the calculation of the active and reactive power output of the PV inverter generation. This strategy is analyzed in the following sections, starting with controller design, SVPWM algorithm, and then ending with the first circuit diagram.

\subsection{Controller design}

In order to control $\mathrm{P} \& \mathrm{Q}$, the output current and voltage adapted to the d-q synchronous rotating frame is presented in [12] and the following modified equations to calculate the real and reactive power in the proposed method.

$$
\begin{gathered}
\left\{\begin{array}{c}
u_{\text {and }}=-\left[K_{p p}+\frac{K_{P I}}{s}\right]\left(P^{*}-P\right)+u_{d x} \\
u_{a n q}=\left[K_{Q p}-\frac{K_{Q I}}{s}\right]\left(Q^{*}-Q\right)+u_{q x}
\end{array}\right\} \\
\left\{\begin{array}{c}
u_{d x}=u_{s m}-\frac{2 R P}{u_{s m}}-\frac{2 \omega L Q}{u_{s m}} \\
u_{q x}=\frac{2 R Q}{u_{s m}}-\frac{2 \omega L P}{u_{s m}}
\end{array}\right\}
\end{gathered}
$$

The adopted PI-DPC is represented by the two equations (1) and (2) to calculate the active and reactive power. The final stage is the transformation from the rotating frame two-axis $(d-q)$ frame to ( $\alpha-$ $\beta$ ) stationary as an input to the SVPWM that will generate the pulses to drive the power.

\subsection{MPPT}

MPPT has been used widely with different techniques to get the maximum capable power from the solar systems, Perturb and observe (P\&O) technique is integrated with the proposed method to attain a DC voltage that allows maximum power from the PV string [13]. P-V and V-I characteristic curves depend on irradiation in $\left(\mathrm{W} / \mathrm{m}^{2}\right)$ and the temperature in (Deg. $\left.\mathrm{C}^{\circ}\right)$; these parameters can affect the efficiency of the solar cell without having MPPT algorithm in the system. This paper's considerations are constant temperature, which is $25 \mathrm{C}^{\circ}$, and the varying irradiation four times in $\left(\mathrm{W} / \mathrm{m}^{2}\right)$. A DC reference voltage results from MPPT algorithm to the SVPWM as an integration between the solar systems and the inverter controller to get a maximum stable power output of the solar panel [14].

\subsection{Circuit Diagram}

Figure 1 shows the block diagram of the circuit and control strategy. The diagram is composed of the generation sources of PV arrays, the control block direct power control, two DC-link capacitors, load demand, and a single- phase inverter. The output voltage $V_{\text {out }}$ is compared with a desired output voltage reference, and the error is sent to a PI controller to yield the reference of an active power $P^{*}$. Then the inverter is controlled based on the diagram to generate the power P to trace the reference $\mathrm{P}^{*}$. LPF has been used in this paper. extract the angular frequency $\omega$ from the Ac output voltage $V_{\text {out }}$ has been done by using phase-locked loop (PLL), which is establishing the control method that starts by d-q synchronous reference frame. 


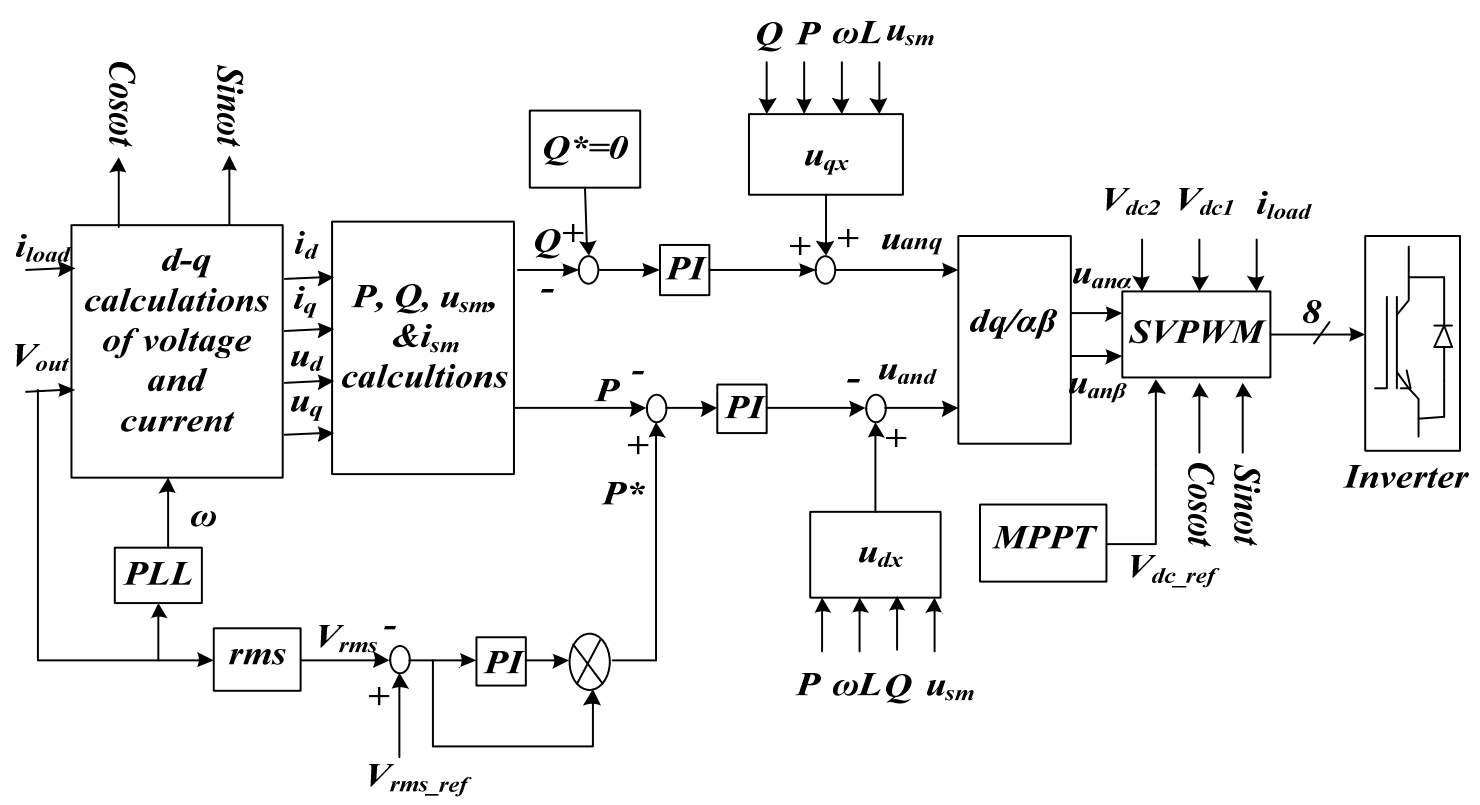

Figure 1. The control strategy diagram

Table 1. Simulation System Parameters

\begin{tabular}{cc}
\hline Parameters & Value \\
\hline The output ac voltage $(\mathrm{rms}) / \mathrm{V}$ & $220 / \mathrm{sqr}(2)$ \\
Sampling and control time $\mathbf{T}_{\mathbf{s}} / \boldsymbol{\mu s}$ & 10 \\
Switching frequency $\mathbf{f}_{\mathbf{s}} / \mathbf{K H z}$ & 1.25 \\
DC-link capacitors $\mathbf{C}_{\mathbf{1}}=\mathbf{C}_{\mathbf{2}} / \mathrm{mF}$ & 3.0 \\
The varying ratting load watt & $190-325$ \\
L-C low pass filter L/mH $\& \mathbf{C}_{\mathbf{3}} / \mathrm{mF}$ respectively & $10 \& 1.0$ \\
The frequency of the output voltage f $/ \mathrm{Hz}$ & 50 \\
The cut-off frequency of the LPF in Fig.2/Hz & 5 \\
Open circuit of each PV panel/V & 37.6 \\
Short circuit current of each PV panel $/ \mathrm{A}$ & 8.55 \\
\hline
\end{tabular}

\section{SIMULATION RESULTS}

This simulation examines a single-phase grid-connected PV system in depth, using MATLAB/SIMULINK tools in order to evaluate and analyze the performance of each element of the system as shown in Figure 2 and 3. The proposed method will be discussed and further examined using multiple scenarios to demonstrate the strategies under various conditions. The analysis is both practical and efficient. The simulations are presented using temperature and irradiance as the variables. The strategies called Space Vector Pulse Width Modulation for single-phase three-level inverter have been introduced and integrated with the P\&O MPPT algorithm. The proposed method examines the algorithm with its changes based on the integrated facets of each scenario. The simulation systems are built based on the circuits diagram and its parameters as shown in Figures 1 and table 1. To verify the performance of the proposed method under different conditions, the strategy is tested and compared in three scenarios. Each scenario shows simulation waveforms of the irradiance, temperature, real power $P$, reactive power $Q$, PV output voltage $V_{d c}$, load voltage $V_{\text {out }}$, and load current $i_{\text {load. }}$.

In order to verify the performance of the proposed method under different conditions, this strategy is tested and compared in four scenarios. Each scenario shows simulation waveforms of the irradiance, temperature, active power $P$, reactive power $Q$, PV output voltage $V_{d c}$, load voltage $V_{\text {out }}$, and load current $i_{\text {load }}$. 


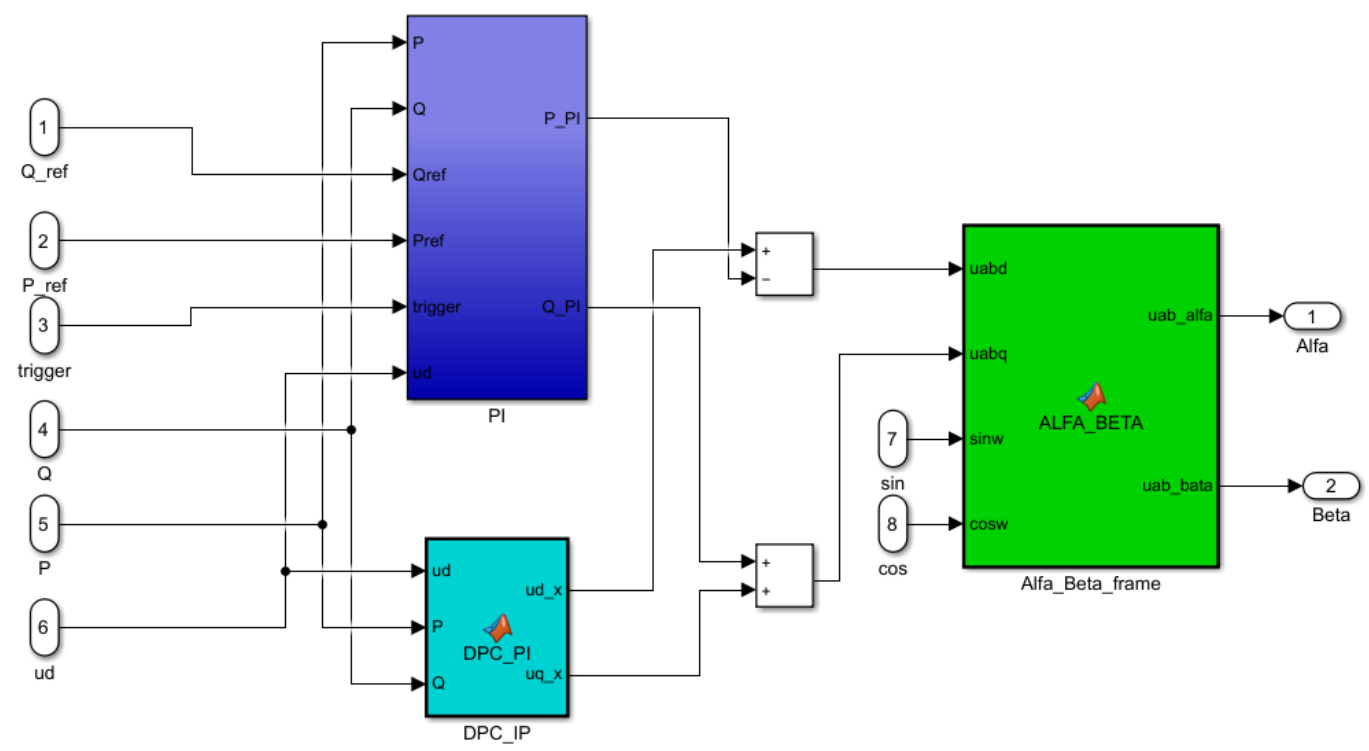

Figure 2 Simulation model of Alfa-Beta transformation

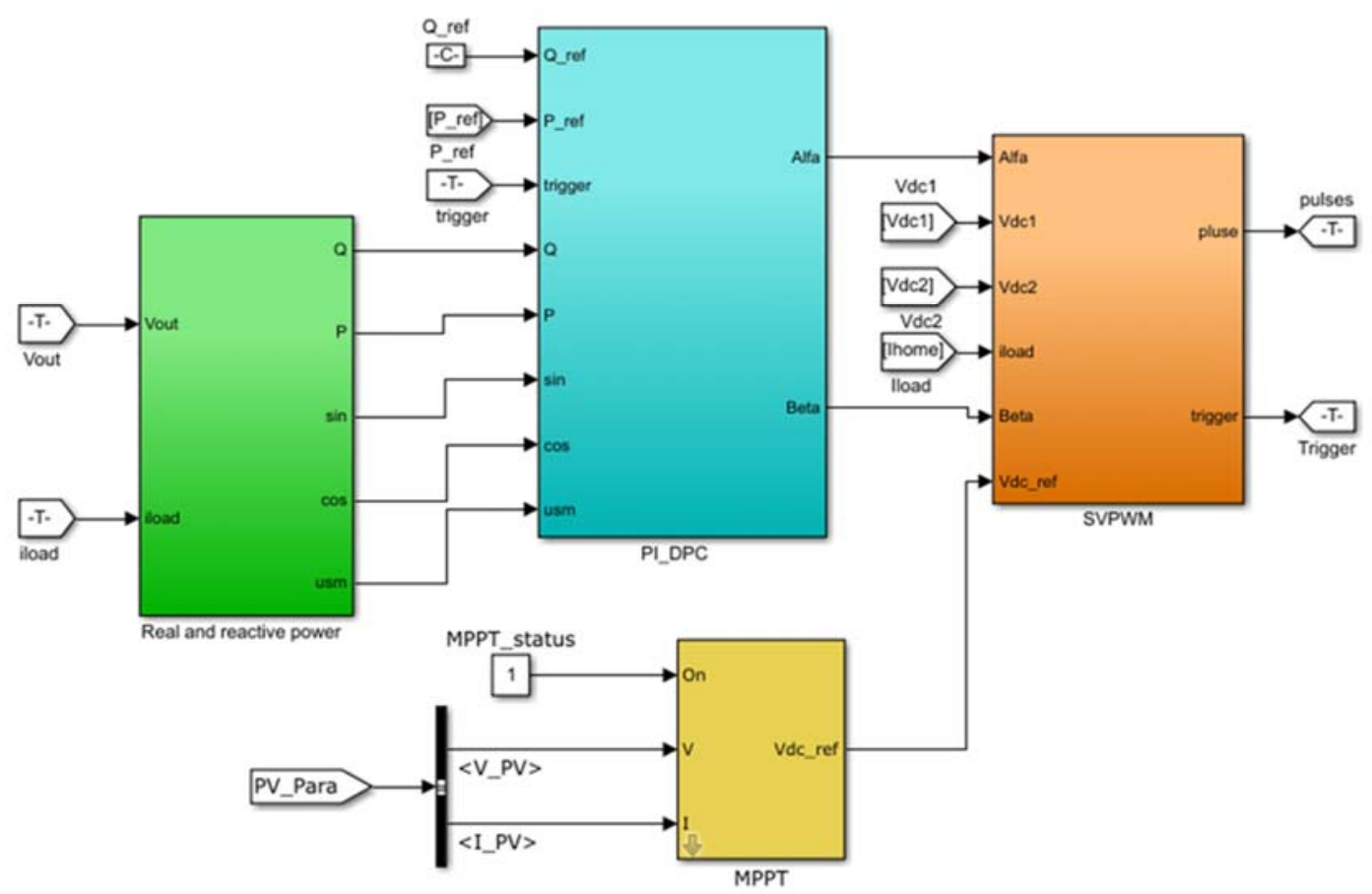

Figure 3 Simulation model of SVPWM control scheme

\subsection{Scenario A: Varying Load and Solar Irradiation with Constant Temperature}

In this scenario, the load and solar irradiation are varying with $\mathrm{T}$ constant at $25^{\circ} \mathrm{C}$. The average load demand is set to jump from 190 to $250 \mathrm{~W}$ at $t=2 \mathrm{~s}$. The solar irradiance changes four times. It starts with 650 $\mathrm{W} / \mathrm{m}^{2}$ and ris es to $750 \mathrm{~W} / \mathrm{m}^{2}$ at $t=2 \mathrm{~s}$, then rises further to $1000 \mathrm{~W} / \mathrm{m}^{2}$ at $t=3 \mathrm{~s}$, and eventually drops to 750 $\mathrm{W} / \mathrm{m}^{2}$ at $t=4 \mathrm{~s}$. As displayed in Figure 4 , the PV output voltage is varying with the PV irradiation changes, but it is clear that the active power output $\mathrm{P}$ can achieve a faster response and shows a stable waveform 
regardless of the irradiance variation. Also, the output voltage and current are also stable sinusoidal waveforms.
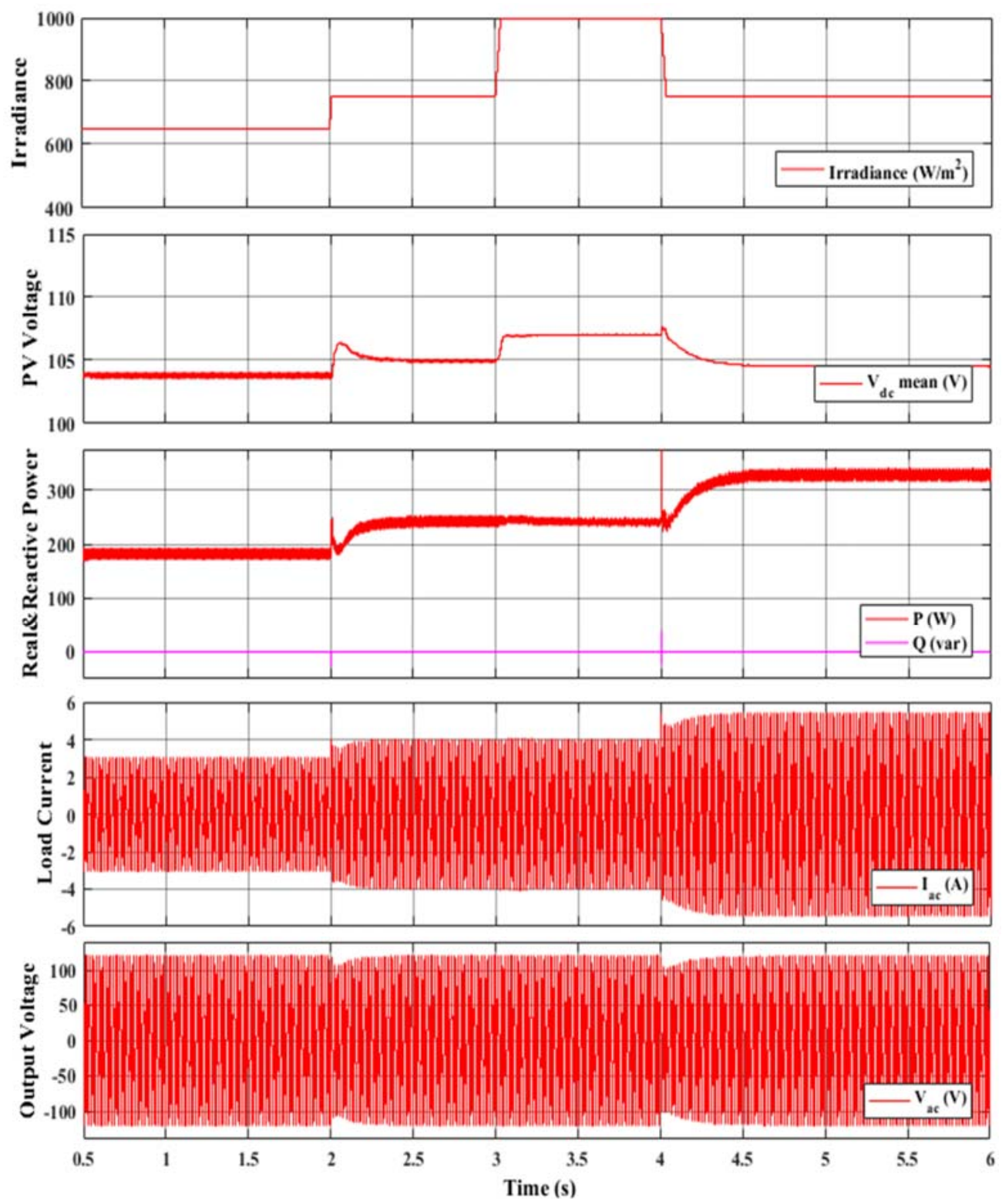

Figure 4 Waveforms of scenario A

\subsection{Scenario B: Varying Load and Solar Temperature with Constant Irradiation}

In the second scenario, the temperature and the load are varying with irradiation constant at 1000 $\mathrm{W} / \mathrm{m}^{2}$. The average load demand profile is the same as the one in Scenario 2. The solar temperature changes four times. It starts with $18{ }^{\circ} \mathrm{C}$ and rises to $25^{\circ} \mathrm{C}$ at $t=1 \mathrm{~s}$, then rises further to $30{ }^{\circ} \mathrm{C}$ at $t=2 \mathrm{~s}$, before eventually dropping to $25^{\circ} \mathrm{C}$ at $t=4 \mathrm{~s}$. As exhibited in Figure 5, the PV output voltage is fluctuating with the solar temperature variations, but it is clear that the adapted PI- DPC controller can attain a faster dynamic response, showing a stable output real power waveform apart from the solar T variations. In addition, the output voltage and current are also stable sinusoidal waveforms. Moreover, the reactive power is controlled to stay close to zero for achieving a unity power factor. 

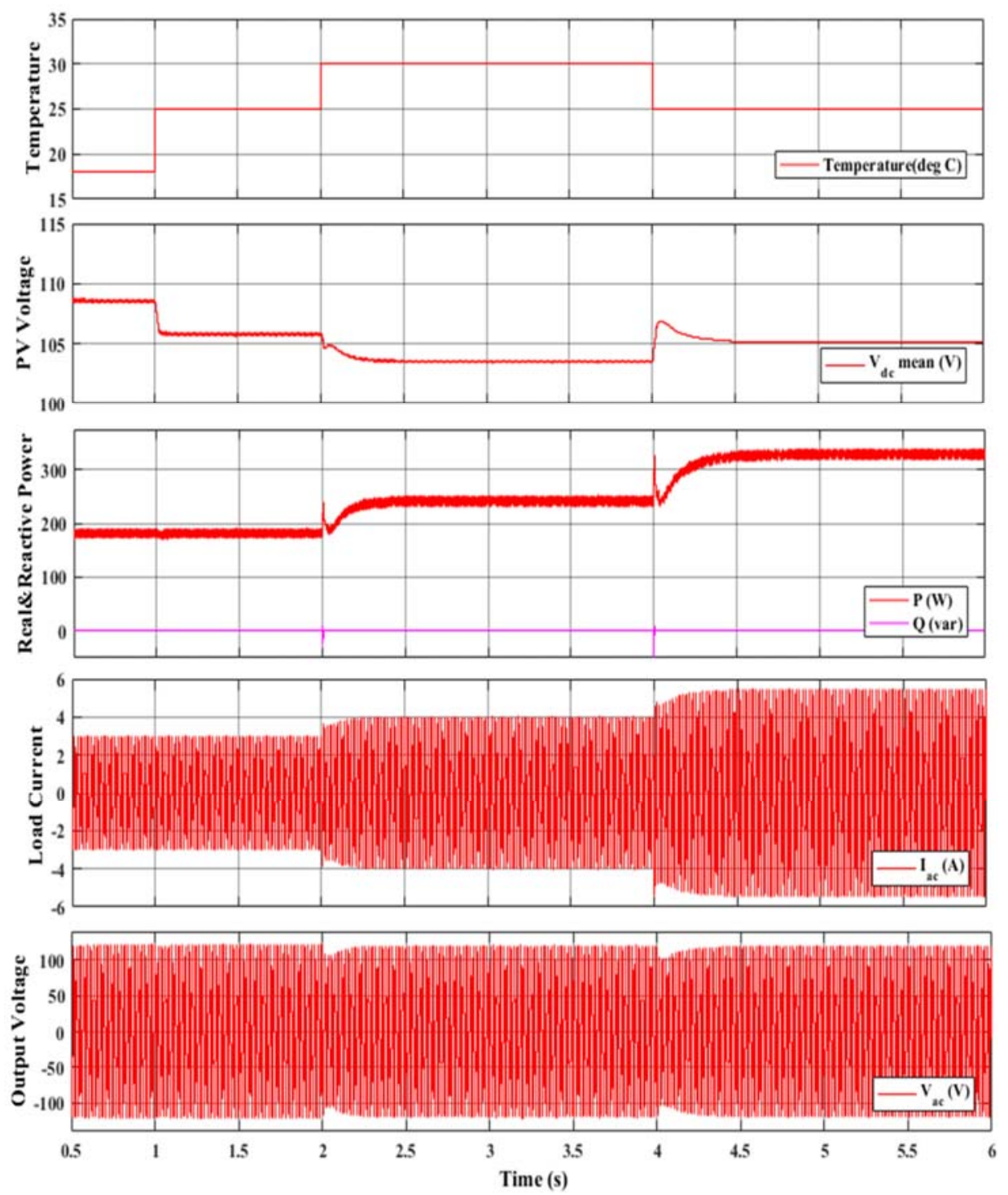

Figure 5 Waveforms of scenario B

\subsection{Scenario C: Varying Solar Irradiation and Temperature with Varying Load}

In this scenario, the solar temperature and the irradiation are varying with a changing load. The load demand and solar S profiles are the same as the one in Scenario 2, and the solar T profile is the same as the one in Scenario 3. It can be seen in Figure 6 that the variations of the solar T and S resulted in the fluctuation of PV output voltage, but it is clear that the adapted PI- DPC controller indicates a faster dynamic response that shows a stable output active power waveform aside from stable sinusoidal waveforms of the output voltage and current.

Apparently, in all three scenarios, the inverter can be controlled to fast-track the sudden change of the load demand; also, the reactive power is regulated to zero no matter how much real power is generated. In addition, the output voltage of the inverter is controlled to follow the grid with minimal influence from the sudden load change and the output voltage will return to the steady-state value soon after the disturbance. Only the output current changes to track the change of output power.

The proposed methods yield slightly similar results and display a significant decrease in the THD. As listed in Table 2, the simulation outcomes of the proposed technique denoted a significant elimination range of THD and fulfilled the intended amplitude. Additionally, the THD results of all three scenarios control techniques meet IEEE Standards which is a maximum limit of 5\%. 

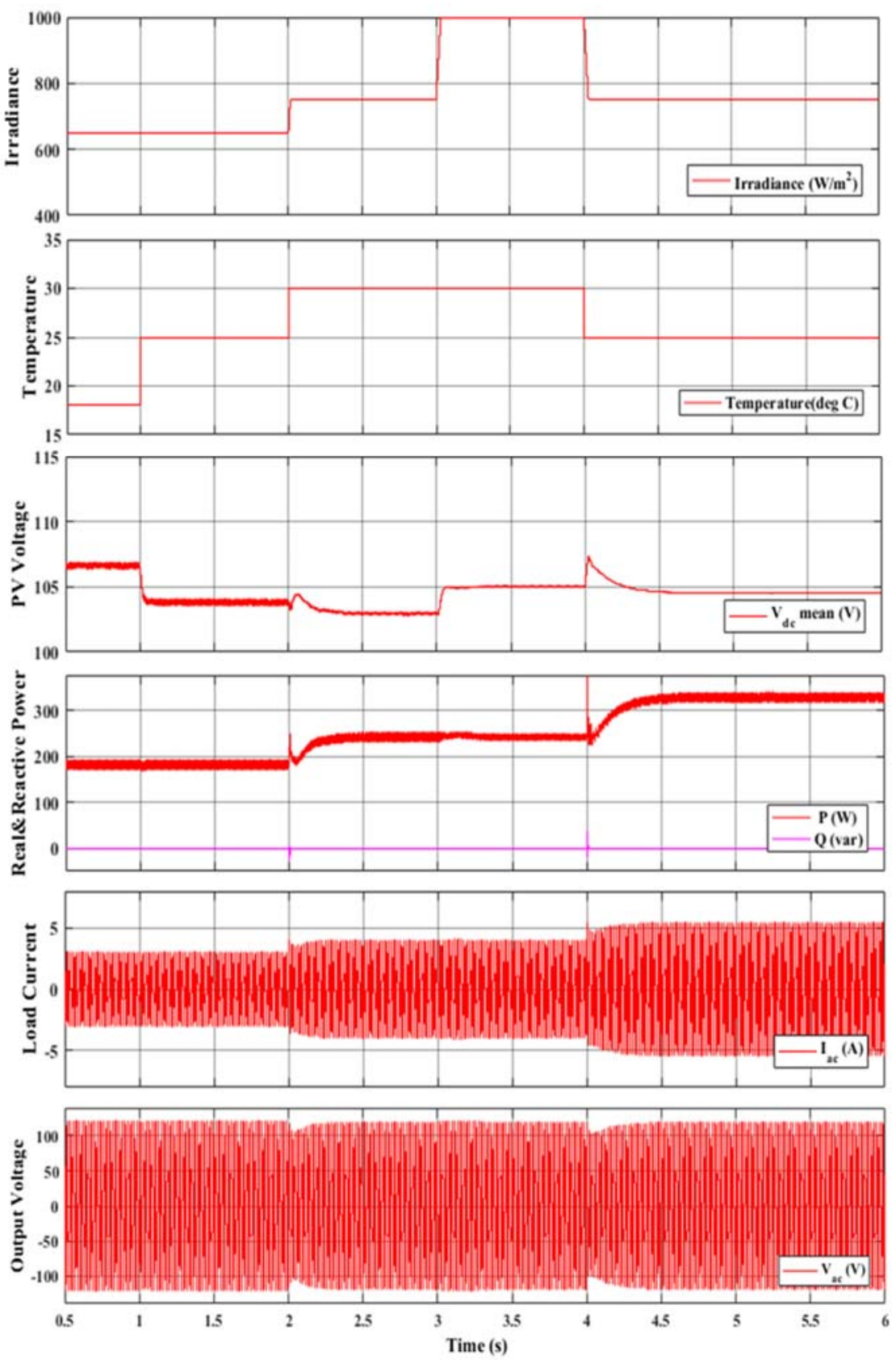

Figure 6 Waveforms of scenario C

Table 2 The THD comparison for each scenario

\begin{tabular}{cc}
\hline Scenarios & THD \\
\hline Scenario A & $2.34 \%$ \\
Scenario B & $2.29 \%$ \\
Scenario C & $2.27 \%$ \\
\hline
\end{tabular}

\section{CONCLUSION}

In this article, a tracker power control method is proposed for a single-phase PV inverter. A modified DPC-PI controller is used in the voltage control loop for tracking the active reference power. A notch filter is added to the DC-link voltage feedback signal to filter out the double line frequency ripple 
component appeared on the DC-link voltage so that this ripple component does not distort the output grid current. Also, a new SVPWM for single-phase grid-connected PV inverters is adopted, which can work on multiple switching frequencies. The presented algorithm performance shows promising results during the sudden load change. The algorithm potent is verified by the simulation results.

\section{REFERENCES}

[1] F. E. Aamri, H. Maker, A. Mouhsen, and M. Harmouchi, "A new strategy to control the active and reactive power for single phase grid-connected PV inverter," 2015 3rd International Renewable and Sustainable Energy Conference (IRSEC), Dec. 2015.

[2] Geoff Walker. "Evaluating MPPT Converter Topologies Using Matlab PV Model", Department of Computer Science and Electrical Engineering, University of Queensland.

[3] Zaid Hussein Ali, Abdullah Khalid Ahmed, Amer Tayes Saeed, "Modeling Solar Modules Performance Under Temperature and Solar Radiation of Western Iraq", International Journal of Power Electronics and Drive System (IJPEDS), Vol. 9, No. 4, December 2018, pp. 1842-1850

[4] Mohammed Qasim Taha, Aymen Lpiza, "Design a New PWM Switching Technique in Multilevel Converters", IEEE Connecticut Conference on Industrial Electronics Technology \& Automation 2016, University of Bridgeport, CT, United States of America, October 14, 2016 - October 15, 2016.

[5] Karteek Gummi and Mehdi Ferdows, "Double-Input DC-DC Power Electronic Converters for Electric-Drive Vehicles-Topology Exploration and Synthesis Using a Single-Pole Triple-Throw Switchl", IEEE Transactions on Industrial Electronics, Vol. 57, No. 2, February 2010.

[6] A. Lavanya, K. Vijaya kumar, J. Divya Navamani, "Topological Comparison of Dual-Input DC-DC Converters", International Journal of Power Electronics and Drive System (IJPEDS), Vol. 8, No. 2, June 2017, pp. 804 811

[7] M. A. Arjona, F. A. Ramirez, and C. Hernandez, "Analysis of Two Current Injection Strategies of a Grid Connected Single-Phase PV-SVPWM Inverter," 2010 IEEE Electronics, Robotics and Automotive Mechanics Conference, pp. 690-695, Sep. 2010.

[8] S. Jiang, H. Wu, W. Wang, and D. Xu, "A Novel Algorithm to Improve Dynamic Response of Single-Phase GridConnected PV Inverter," 2010 First International Conference on Pervasive Computing Signal Processing and Applications, pp. 1069-1072, 2010.

[9] Mohammed Qasim Taha, Mustafa H. Al-Jumaili, Abdullah Khalid Ahmed, "Modeling the dielectric mediums impact on coaxial transmission line performance", Journal of Engineering and Applied Sciences, Volume 13 Issue 20, 2018.

[10] Mustafa Hamid Al-Jumaili, Ahmed Subhi Abdalkafor, Mohammed Qasim Taha, "Analysis of the Hard and Soft Shading Impact on Photovoltaic Module Performance Using Solar Module Tester", International Journal of Power Electronics and Drive Systems (IJPEDS), Vol 10, No 2: June 2019

[11] B. Crowhurst, E. F. El-Saadany, L. El Chaar, and L. A. Lamont, "Single-Phase Grid-tie Inverter Control Using DQ Transform for Active and Reactive Load Power Compensation," 2010 IEEE Int. Conf. Power Energy, pp. 489-494, 2010.

[12] Mohammed Q. Taha, Qusay H. Eesse and Salih Mohammed Salih, "Mathematical Modeling of different Photovoltaic Modules", Journal of telecommunications, Volume 11, Issue 2, pp. 59-64, December, (2011).

[13] N.A. Zainal, A.R. Yusoff, "Modelling of Photovoltaic Module Using Matlab Simulink", IOP Conference Series: Materials Science and Engineering, pp. 012137, 2016.

[14] Z. H. Ali, J. Zhao, E. Manla, J. Ma, W. Song, "Novel direct power control of single-phase three-level SVPWM inverter for photovoltaic generation", 2017 IEEE Power \& Energy Society Innovative Smart Grid Technologies Conference (ISGT), pp. 1-5, 2017. 